\title{
Artelogie
}

artelogie Recherche sur les arts, le patrimoine et la littérature de l'Amérique latine

$14 \mid 2019$

Sensibilités : Arts, littératures et patrimoine en Amérique latine

\section{Tabúes y pasiones. Ideas, afectos y prácticas en el cruce del Atlántico}

Rosalina Estrada Urroz

\section{(2) OpenEdition \\ 12 Journals}

Edición electrónica

URL: http://journals.openedition.org/artelogie/3718

DOI: 10.4000/artelogie.3718

ISSN: 2115-6395

Editor

Association ESCAL

Referencia electrónica

Rosalina Estrada Urroz, « Tabúes y pasiones. Ideas, afectos y prácticas en el cruce del Atlántico », Artelogie [En línea], 14 | 2019, Publicado el 31 julio 2019, consultado el 13 septiembre 2019. URL :

http://journals.openedition.org/artelogie/3718; DOI : 10.4000/artelogie.3718

Este documento fue generado automáticamente el 13 septiembre 2019

Association ESCAL 


\title{
Tabúes y pasiones. Ideas, afectos y prácticas en el cruce del Atlántico
}

\author{
Rosalina Estrada Urroz
}

1 Cómo pensar las sensibilidades desde diferentes espacios sociales y académicos, cómo ir de un lugar a otro y encontrar en el camino la pérdida del espacio propio, en el cual se ha vivido muchos años o solamente algún tiempo. Cómo comprender la llegada a México de ideas a través de libros, hombres y mujeres, desde el mundo médico que es representativo, desde el diplomático o desde el mismo espacio social que se construye. A los migrantes y a los que permanecen en el punto de partida, les atraviesa pronto la añoranza y la nostalgia, quizá hayan vivido la partida del otro desde la esperanza, y con el transcurrir del tiempo la ausencia se vuelve una costumbre o un fardo que hay que soportar. El trayecto hacia otro horizonte es corto, pero el tiempo pasa y en él se viven diferentes acontecimientos. Así, desde los dos lugares, surge la necesidad de saber de él, de ella, de ellos. Desde la angustia del silencio, desde los años sin tener noticias del otro, duele el olvido, la hechura de otra vida, el abandono y el descuido y la imperiosa necesidad de ayuda que oscila entre el amor y el interés. Alguna vez se recibe una nota que no satisface. En la migración siempre hay dos partes, se trata de cadenas afectivas en riesgo de romperse. El tiempo y la búsqueda de nuevos cielos trabajan en contra; para los que se quedan, lo más llamativo es la esperanza. Aquel que parte aparece como quien compensará la ausencia algún día.

2 Desde la historia de las sensibilidades, distintas perspectivas nos han llevado a abordar nuestros problemas de investigación a partir de la historia intelectual, las representaciones y los sentimientos de viajeros y migrantes. Los tres aspectos parecerían inseparables. Ligadas a través del viaje, personas e ideas son vistas desde la recepción y la apropiación. Cruzar la frontera desde el mar adquiere otro significado, los puertos de partida y de llegada son, desde el afecto y la cultura, paisajes a rememorar. 


\section{Desde la historia intelectual, polémicas y controversias}

3 Los temas de investigación nos atraviesan. Me encontré con ellas, mujeres dedicadas a la prostitución, por una nota del archivo del ayuntamiento que refería la inconformidad de las matronas por la competencia desleal de las "clandestinas" que cobraban menores tarifas y no tenían que pagar impuestos. Esto me introdujo en el tema sin saber hacia dónde iría. El camino ha sido sinuoso: Parent du Châtelet fue mi primer acercamiento, por supuesto que en ello jugó un papel fundamental Corbin y los planteamientos de los higienistas franceses y su recepción en México.

4 La polémica es un lugar privilegiado para comprender los planteamientos de los médicos mexicanos, pues en ella se despliegan conocimientos, se construyen y expresan las diversas influencias de que han sido objeto. Como señala Said, las ideas viajan y se instalan de forma parcial, influenciadas por la política. El tiempo establece las distancias entre el momento de enunciación y de recepción. Basta traer a colación el libro de Ricord, Traité pratique de maladies venerienne, ${ }^{1}$ publicado por primera vez en $1838 \mathrm{y}$ multicitado por las diferentes producciones en las últimas décadas del siglo XX. Trabajos que estudian, a grandes rasgos, la discusión y aplicación del reglamentarismo y sus efectos en la práctica y control de la prostitución, considerando la enfermedad como un elemento crucial. En ello podemos constatar, de manera general, la influencia de la medicina europea y la predominancia de la francesa. A medida que avanza el siglo XX, la rivalidad entre Alemania y Francia se hace evidente, a la vez que se presenta el abolicionismo como una posibilidad.

5 Estas discusiones tienen eco en diferentes escritos. Gamboa en su novela Santa, Lara y Pardo en el libro La prostitución en México son receptores de estos planteamientos en una simbiosis que se manifiesta en la continuidad de la moral y sus metáforas. Eduardo Lavalle Carvajal (ESTRADA, 2008: p.163-193). se refiere, de forma directa, a la obra de Lara y Pardo en dos ocasiones: la primera en el texto "Profilaxis venérea, medios prácticos de fácil aplicación y de prontos resultados", ${ }^{2}$ y la segunda en una reseña, publicada en el Observador Médico. ${ }^{3}$ A pesar de la distancia que lo separa, de Lara y Pardo y Gamboa comparten. París es para ellos una referencia constante. Cuando el primero se extraña del número de prostitutas inscritas y de que éste sea cercano a las registradas en la ciudad de París, Lavalle asevera que en México aparecen más inscritas de las que son, y en París menos de las que ejercen; para él: "En la ciudad clásica... el grueso del ejército de la prostitución social y legalmente indiscutible del que diariamente hace formación y desfila por 'Folies Bergères', 'Folies Marigny', 'Bullier', 'Moulin Rouge', 'Jardin de Paris', cabarets, brasseries, cafés, etc., etc., no lleva libretas en las medias". ${ }^{4}$

6 Pero en la argumentación de Lavalle en contra de Lara y Pardo también encontramos su peculiar concepción de las prostitutas y de las clases populares. Sobre la situación de esclavitud que las mujeres viven en los burdeles, afirma que se revela en aquellos de estilo español o francés antiguo, y pondera la gestión de las matronas americanas, quienes explotan admirablemente su negocio, "sin esclavizar los huéspedes de sus casas, quizá porque éstas tienen cierto grado de civilización". A su vez, insiste en que el reglamento, lejos de fomentar esta esclavitud, tiene como objetivo moderarla e incluso abolirla. 
7 Lavalle Carvajal hace gala de su conocimiento del ambiente prostibulario francés y rebate a Lara y Pardo oponiendo sofisticación francesa con naturalidad mexicana:

El burdel en esta metrópoli necesita carne fresca. Las conservas en "afeite" no tienen consumo. Los visitantes son jóvenes y ávidos de amores naturales. Los amores artificiales de las artistas decanas de las mancebías europeas, no las necesitamos todavía, aunque así quieren hacerlo creer los pervertidos de palabras, que apenas husmearon las depravaciones genésicas de la Lutecia moderna durante una quincena. ${ }^{5}$

8 En su reseña se revela como el irrefutable especialista en la materia. Las diferencias que señala con Lara y Pardo rebasan la opinión para situarse en el campo de la política, cuestión que se relaciona con el lugar que cada uno tiene o quiere ocupar en el mundo médico. Para confirmar su autoridad subraya que la profilaxis antivenérea le ha "apasionado desde que, como estudiante", fue "asiduo concurrente á las clínicas y al servicio especial del Profesor Fournier en el Hospital de St. Louis de París". (LAVALLE CARBAJAL, 1909: p.308-365).

Estamos tentados a hacernos la gran pregunta: ¿es posible encontrar en este pensamiento científico originalidad mexicana?, o quizá sería más importante tratar de apropiarnos de esa compleja relación que se establece entre las ideas científicas que vienen de Europa con las ideas prevalecientes en nuestro país, sobre la prostitución y curación de las enfermedades venéreas, en particular la sífilis, sin olvidar aquello que se ha leído y aprehendido y el estado de incertidumbre en el conocimiento de la enfermedad y su curación. La medicina mexicana copia de manera particular y esto nutre las polémicas que, como diría Said, son apropiadas sólo parcialmente, no corresponden a su situación original. Si vamos más allá, esta apropiación o recepción se realiza con otros sistemas de pensamiento, que tienen vinculación con el pensamiento médico, pero también con las representaciones que sobre la enfermedad se construyen, alimentadas en este caso por la moral. (PALTI, 2006: p.149-179). Además se establecen adhesiones y preferencias a una u otra escuela, sin olvidar las fidelidades que cada quien tiene con sus orígenes disciplinarios y con la política.

Frida Gorbach, al referirse al difusionismo, insiste en no olvidar la política, ${ }^{6}$ dimensión que según el tiempo adquiere características particulares. En este caso se trata, sobre todo, de los cuerpos desviados que hay que disciplinar, aquellos peligrosos para la salud y con incidencia en la herencia. Las dificultades que enfrentamos tienen relación con esa dualidad planteada en las "ideas fuera de lugar", en especial si pensamos que ese proceso de recepción se produce de manera "defectuosa", pues las teorías parten de realidades distintas y la mirada sobre ellas adquiere particularidades que obedecen a una mirada "local" entre comillas, pues están también influenciadas por la aparente "universalidad". Así, nacionalismos, racismos y colonialismo aparecen como telón de fondo en la llegada de las ideas que viajan. Por supuesto que detrás de esta visión se encuentra el control del cuerpo, la sexualidad y las consecuencias de la herencia, la sífilis hereditaria y la raza y, con ello, la gobernabilidad.

\section{La perspectiva de las sensibilidades desde el cuerpo y las emociones}

11 Desde la perspectiva de las sensibilidades, como sostiene Wickberg, (2007: p.661-684). transitamos de las representaciones hacia las formas de percepción y sentimiento. Quizá, 
pensar en la apertura de las subjetividades nos permite tener flexibilidad. Los afectos, como estados de la mente y del cuerpo, relacionados con los sentimientos y emociones, se desarrollan en tres tipos primarios: deleite o placer, pena y deseo o apetito. Afecto o pasión aparecerían como siempre confusas, pero podríamos estar de acuerdo que si se ven desde una perspectiva polifónica es más fácil que lleguemos a un consenso, no nos casamos con emoción o afecto, quizá no podamos dejar de lado los términos "sensibilidades" y "pasión" que parecen indiscutibles. El afecto es la fuerza útil del cuerpo, habilidad de afectar y ser afectado. Es una intensidad personal que corresponde al pasaje de una experiencia del cuerpo a otra que implica capacidad de aumentar o disminuir la capacidad de actuar. (MORAÑA, SÁNCHEZ PRADO, 2012: p.313-337.)

Las ideas y los libros viajan, como lo sostiene Said, en la travesía se adaptan, parcializan y se apropian de diferente manera por hombres y mujeres que según el tiempo y la geografía tienen sensibilidades comunes o diversas. Los viajeros que pueblan tierras lejanas no se atreverían a atravesar montañas, océanos y tempestades si no los inspirase grandes ilusiones; éstas nutren la decisión de la partida y alimentan a lo largo del viaje cartas, conversaciones y planes. Este imaginario sobre la tierra prometida se encuentra nutrido por palabras de otros viajantes; ellos alimentan la utopía, construida como proyecto antes de llegar a puerto mexicano.

13 Inspirados en Humboldt, numerosos viajeros franceses siguen su ruta y ven en México uno de los lugares que podía contribuir al conocimiento científico y también a la riqueza. La minería ejerce un gran atractivo para algunos, mientras que otros se alimentan del deseo de fortuna en el comercio. Como señala Chantal Cramausell, de manera temprana, los migrantes franceses llegan a México por diversas razones, "gente de origen humilde, dispuesta a dejar su lugar de origen, en busca de una vida mejor". (CRAMAUSSEL, 1998: p.333-363.)

Desde el siglo XVIII, a través del viaje que realiza Thiery de Menoville a Oaxaca para apropiarse de la cochinilla, nos preguntamos sobre las sensibilidades del científico ilustrado en el tiempo. De diversa forma, el cuerpo, el corazón en particular, es afectado por el viaje, por el paisaje, por la belleza femenina, pero también por esa pasión botánica, por el descubrimiento y por la gloria de la aventura. De Mornet señala que los hombres de este siglo habrían conocido todas las formas del pensamiento contemporáneo; con un espíritu analítico delinearon el método, la verdad lógica y abstracta, pero: "Por precisas y numerosas que sean las razones de la razón y las leyes de nuestras ciencias, no pueden darnos la explicación de nuestro destino, nuestras razones para obrar ni el secreto de la felicidad". Y no podrían percibirse "estas razones y este secreto más que por otra luz, la del sentimiento, la del corazón que hoy llamamos intuición". De Mornet insiste en la ambivalencia del pensamiento, pues "cuando la razón o la experiencia científica no están de acuerdo con el corazón, los equivocados son la razón y la experiencia" (MORNET, 1988: p.178). Como Rousseau, Menonville parecería estar dividido, entre "sentido y sentimiento, entre racionalidad y emotividad, placer y utilidad." (HOYSTAD, 2007: p.192.) Quizá, desde ahí podamos observarlo, sin menospreciar su búsqueda de gloria a través de la aventura señalada por Venayre, génesis de una mística moderna, la cual recupera en el viaje la historia natural y, pensando en Arlette Farge, la afección, la vida frágil, y en el mar y el cielo, el paisaje de Corbin.

15 La pasión de Menonville por la cochinilla parece ser vieja. En Lorrraine, siendo adolescente, escucha sobre este rojo, conoce que en 1555 un viajero inglés, Robert Tomson, pudo determinar de dónde provenía y dijo que la "cochinilla no es un gusano o 
una mosca, como algunos dicen, pero una mora que crece en ciertos bulbos". ${ }^{7}$ (FINLAY, 2002: p.150-151.) Menonville tenía claro que se trataba de un insecto, pero no sabía cómo distinguir la calidad del mexicano, denominado fino, y descubre que Oaxaca es el centro de producción de este apreciado bien.

Al arribar a Veracruz se hace pasar por catalán, y no puede evitar su jolie coeur. Encuentra una bella mujer en una casa de indígenas, la observa casi desnuda y descubre que no tiene ningún defecto, sabe que está casada y con hijos; sus encantos lo excitan y está a punto de ofrecerle una moneda de oro, pero una voz interna lo hace retornar a su otra pasión: la búsqueda de la cochinilla, y deja el lugar sin decir palabra alguna:

Lo que me llamó la atención y me encantó más que nada, fue la perfecta belleza de la india ama del jacal. Le buscaba en vano algunos defectos. Estaba medio desnuda, ya que sólo tenía una falda de muselina con holanes, adornada con un cordoncito color de rosa y una camisa que dejaba al descubierto sus hombros. Su talla me pareció igual en regularidades con los rasgos de su cara. Le dije que era muy bella, y esto parece que le gustó... le hice muchas preguntas. Así supe que estaba casada... Me atreví a hacer brillar ante sus ojos un poco de oro, pero volviendo rápidamente en mi me dije: Desgraciado ¿Por quién te tomas?, ¿es éste el fin de tu trabajo? ... ¡Oh insensato!

Más que dividido, esa oscilación del corazón muestra al viajero en un tiempo donde lo sensible habita la razón. Un corazón que late y piensa, hoy no parece ser una novedad. En su último libro, Damasio (2018: p.12.) señala que los sentimientos no son "independientes de la fabricación del cerebro. Son el resultado de un cooperativo compañerismo de cuerpo y cerebro, interactuando por medio de un libre orden de las moléculas químicas y trayectos nerviosos". Maffesoli y las vísceras pensantes nos devuelven a esta experiencia; el hombre que se lleva la cochinilla deja ver, a través de su relato, el tiempo que habita, y en su entusiasmo nutrido por la galantería, la estética y la ficción muestra la pasión e imaginación que lo acompañan. Si nos trasladamos a la historia de la ciencia y pensamos la apropiación del conocimiento y los celos que éste provoca, tal vez, tendríamos mayores indicios del saber y su circulación. Bertholet, jefe administrativo de la Manufacture de Gobelins, en su tratado sobre el teñido de 1791, exalta a Thiery como un conquistador. En 1794, el científico mexicano José Antonio Alzate describe la obra en su primera edición y considera que no posee datos relevantes. (SALAZAR, 2010: p.1-30).

El viaje de Menonville es arduo, igual que su pasión; su corazón atribulado vislumbra como botánico la posibilidad del fracaso. Lo vive así en su retorno a Gallatitlán, al descubrir que las plantas adquiridas en Oaxaca se deterioran y animado por la memoria de su primer encuentro con la cochinilla visita a su amigo, el indio que ya ha cosechado y recoge ahí cuatro pies de nopal por los cuales paga seis reales:

[...] recogí esos nopales, así como las otras cuatro piezas que obtuve en Los-Cues, fue tan sólo por precaución y para que no se me reprochara haber olvidado algo. Así fue cómo no tuve ningún éxito en las ramas cargadas de cochinillas que había comprado en Guaxaca y en San Juan Delrey, en las que había puesto todas mis esperanzas, y tuve el dolor de verlas morir sucesivamente podridas y verme obligado a arrojarlas en el Golfo de México. Fueros estas nuevas plantas, con las que menos contaba, a las que debí mi éxito, porque son las únicas que subsistieron y se multiplicaron. (MENONVILLE, 1786: p.216).

19 La publicación de su viaje por el círculo de los filadelfos de Santo Domingo y el nombramiento de botanista del rey muestra el interés por su obra y su saber. En su escritura no deja de mostrarse como un hombre de su tiempo, en una constante oscilación entre esos dos corazones, el que admira y palpita por el paisaje de montañas, ríos y 
mujeres, y el que se arriesga ante flores, hojas y bulbos, observa y roba a la naturaleza mexicana uno de sus tesoros.

\section{Gestos y palabras, la correspondencia, una fuente fundamental}

Viajeros y migrantes atraviesan las grandes aguas y se instalan en México. Conocemos de ellos a través de documentos varios. Para apropiarnos de las vicisitudes del viaje, así como de las relaciones que mantienen con familiares y amigos, la correspondencia es un lugar privilegiado. Por medio de los archivos repatriados de los consulados franceses en México y América Latina hemos podido leer una infinidad de cartas; en ellas se dibujan distintos sentimientos: pesares y vivencias de hombres y mujeres provocados por la partida. Según señalan algunos autores que trabajan sobre el género epistolar, ${ }^{8}$ este corpus puede parecer banal: palabras e historias se repiten en un sinfín de fórmulas que quieren decir la misma cosa, fondo martillado al que se recurre a través de palabras estereotipadas e imágenes comunes. El ceremonial se sigue en la mayoría de las misivas: un saludo que excusa la molestia ocasionada, una despedida breve en la que se muestra respeto y agradecimiento por los servicios que se solicitan. ${ }^{9}$ Esta correspondencia constituye un camino para comprender la situación de aquellos que migran y de las familias que permanecen en Francia y continúan con los ojos puestos en el puerto de salida y de llegada y que, en muchos casos, quedan en el desamparo afectivo y económico. Los diferentes sentimientos recorren el tiempo y cambian según sea el éxito o fracaso de la migración. Mujeres solas o engañadas, hijos abandonados, padres que han perdido el sustento, madres, concubinas y esposas que permanecen en tierras francesas y remiten notas de indagación ya sea a través de sus letras o por medio de terceros que tienen mayor autoridad. A la emoción y tristeza de la partida se le agrega la repetida angustia.

21 Acá se revelan los vocablos de la ausencia. Verdadero o inventado lo inusitado puede ser visto como exótico, pero a su pesar deja ver lo oculto que aparece sólo de manera sutil en la vida diaria. Estamos habitados por emociones y gestos, el de lectura y escritura, y en esta tarea nos apropiamos del desfile de documentos. En su análisis requieren de una mirada distinta; producidos en diferentes momentos nos cuidamos del anacronismo, aunque ellos mismos lo padezcan. De acuerdo con Pesaventto, lo sensible, la herida, el punctum de Barthes se devela como una posibilidad. ${ }^{10}$

\section{La memoria habitada por el presente}

Es Said quien me hizo pensar cómo el presente se cierne sobre el pasado. Desde el viaje, el tiempo pasa y la memoria se enciende para recobrarlo; en las misivas existe ese afán y ese acto se ubica en la reminiscencia como un espectro que habita su construcción, el silencio del ausente anima la sospecha de la muerte como, citando a Beckett, lo afirma Wood: ${ }^{11}$ ésta "no nos ha exigido que le reservemos días". En palabras de Cristina Rivera Garza: "La muerte nos dice que las comunidades que ya no están presentes... son también parte de las comunidades creadas en la vida". "The dead tell us that the communities that no longer present... are also part of the communities we create in life." Desde su presente afirma: "nuestros muertos quieren ser parte de nuestra conversación, no nos permiten olvidar" ${ }^{12}$ En la correspondencia el espectro se cierne sobre la memoria; la búsqueda 
oscila entre el estar y no estar, en el sospechar de su ausencia y su comportamiento. Quizá sea el fantasma que "no está muerto ni vivo, ni ausente ni presente, ni efectivo ni operante, ni actual ni virtual, es a la vez pasado y presente, perceptible e imperceptible". Así funciona la memoria y la evocación de la ausencia de aquellos que ya no están más. La presencia y la ausencia inmaterial se manejan en la contradicción, aunque la materialidad se hace presente a través de otros medios que, tal vez, puedan ubicarse en la "necesidad". Pero el fantasma llevado a lo espectral es siempre "inmaterial e inmensurable". (RIBASCASASAYAS, PETERSEN: p.1-11).

Nuestras historias parecen estar habitadas por la ficción. A inicios del siglo XX, ante el fracaso matrimonial, el esposo Locatelli dirige un conjunto de misivas a la madre de su desposada; además, se queja ante el cónsul por la conducta, intenciones y actitudes de la cónyuge y le recrimina por "los sentimientos de su corazón hacia él, así como su hipocresía y la bajeza de su educación"; ${ }^{13}$ transcribe una de las cartas donde la esposa confiesa que cometió una brutalidad al casarse sin amor y que la separación de su marido sería la única forma de liberarse de esa cruz. En la misiva señala el deseo de su pareja de engendrar un hijo, pero ella se alegra de no haberlo concebido, pues habría traído a sufrir a este mundo a un pobre niño. Cuenta los días para el arribo de su madre, cree que ello resolverá su situación. Insiste en que sería más feliz si se hubiera unido a Monsieur Boutin, quien es un hombre afectuoso. Las palabras dibujan sus deseos:

Tengo una idea que puede llevar a buenos resultados: Como veo en un párrafo de la carta de Clémence que habla de una visita que tiene que hacer M. Boutin, podría ser que tú le comuniques de tu intención de venirme a buscar, de hacerme venir! Sé que es muy generoso, me recuerdo de Versalles, en nuestros paseos, no rehusaba nada, él era el que siempre pagaba. Faltaba poco para que me pidiera en matrimonio, yo le gustaba mucho, pues el segundo día me besó. Si no está casado, y si viene a Tours a verte, cuídalo bien...

Alejado del presente es el sueño del pasado, y su anhelo el que habita a la esposa. No podemos pensar el espectro de una manera ligera, pero reflexionar desde él, encarnarlo en el presente de la memoria traducido en la misiva, nos permite descubrir ansias y anhelos dibujados de manera etérea. La correspondencia varia abre una nueva perspectiva, ella revela sentimientos y pasiones de los cuales no está ausente el interés y el extrañamiento, la nostalgia y la melancolía.

El género epistolar parece ser un lugar privilegiado para recuperar sentimientos y pesares. Desde estos documentos abordamos la débil y complicada presencia de mujeres francesas en México a finales del siglo XIX e inicios del XX; ellas cruzan el Atlántico y tocan puerto por decisión propia o arrastradas por otros. Las autoridades consulares no sólo se preocupan por el bienestar de sus ciudadanos, también cuidan de aquellos que transgreden las reglas morales y cometen la osadía de abandonar a sus conyugues e hijos. En estas historias, las ideas sobre la mujer francesa nutren las discusiones. Gamboa muestra en sus diarios su deseo de París y su afán de cocotte, Lavalle compara la carne fresca de la prostituta mexicana con el exceso de los afeites de la francesa. Las autoridades consulares intervienen también por la reputación y el desamor, cuidando el sentimiento del hombre ofendido: "En mi infortunio tengo una satisfacción yo he sido siempre querido y estimado en la familia de mi mujer, por mi conducta y la holgura que he logrado a través de mi trabajo".

Además de una escritura cuidada y respetuosa de las formas, en este conjunto de misivas descubrimos otra cercana a la oralidad, plena de faltas de ortografía y de palabras ininteligibles. Se trata de una escritura fonética imperfecta que tiene el afán de protestar 
y solicitar ayuda y que, de todas maneras, puede sucumbir a la tentación literaria a través del hilo conductor del honor, la sexualidad y la reputación. No podemos descartar en esta escritura, como lo señala Cecile Dauphin, (2000: p.110-121). la intervención de los manuales epistolares y los escribanos. A pesar de que las cartas se encuentran ceñidas por la forma, expresan, a través de palabras cuidadas: sentimientos y deseos, anhelos y logros, así como tristezas y dificultades padecidas. El reclamo del pariente del que hace años no se tiene noticias se presenta como un acto de añoranza, de amor y de necesidad. El cónsul es el receptor y a él le corresponde realizar las indagaciones. A veces, la falta de noticias es corta, en otras ocasiones se alarga por veinte, treinta o hasta cuarenta años. Se inquiere cuando se presentan las circunstancias, algunas veces afectivas, otras de necesidad económica, que hacen urgente la respuesta. En las cartas de familia o de los allegados todos tienen sus razones para querer saber, en algunos casos, la enfermedad es el detonante de sentimientos ante la posibilidad de la muerte. Es ésta una preocupación que va y viene: la madre enferma que quiere ver por última vez a su hijo, o la inquietud por la salud del que se conoce endeble al otro lado del océano. Las palabras se repiten: "mi hijo que...", son los vocablos de la ausencia que cincelan las preguntas, palabras dichas y sentidas. Van de un lado a otro. Las respuestas, si es que existen, no parecen muy frecuentes. Más si por ahí aparecen las cartas no entregadas, nos confirman la carencia de noticias de los dos lados.

Hombres y mujeres se ven involucrados. El viaje es siempre acompañado por aquellos que se quedan; misivas que testimonian el seguimiento y que tienen como objetivo guiar, preguntar y quejarse de la ausencia. Los esposos que dejan a sus mujeres en tierras francesas no viajan solos, en sus trayectorias las misivas de sus parejas los acompañan con consejos, indicaciones para relacionarse y también con reproches. Los sentimientos que se expresan tienen diferentes texturas, desde el interés por los negocios que dejaron progenitores y parientes; el llanto por la ausencia del marido que partió en busca de fortuna, hasta la angustia por los nietos que han quedado solos en tierras mexicanas. En esta correspondencia se muestra ese "otro", el que se queda, y que es pensado dos veces, permanece en la memoria de los que parten como lo muestran unas pocas cartas, pero también se manifiestan en la ausencia. En el momento de pérdida de los lazos se inicia el proceso de búsqueda, se trata de tiempos dispares que corresponden a situaciones particulares; el abandono y la muerte son las circunstancias extremas.

De las misivas extraemos múltiples consideraciones que se expresan en palabras de esperanza, pero también de los riesgos y dificultades que pueden enfrentarse. En ellas vislumbramos no sólo el ansia de fortuna a la que ya nos hemos referido, sino también los valores prevalecientes en una sociedad conservadora, la francesa, donde la mujer juega un rol fundamental en la construcción, preservación y marcha de la familia. No obstante, reconocemos que valores como la moral y el honor viven grandes dificultades, propiciadas por la migración. El que deja Francia o quien permanece en tierras mexicanas, sobre todo las mujeres, están bajo la constante custodia desde el puerto de partida. El comportamiento de aquella que ha migrado sola o ha quedado viuda es siempre sospechoso.

La incertidumbre y las deudas son causas de angustia. Los recursos precarios de los migrantes se reflejan en las dificultades que enfrentan para pagar sus obligaciones y eviar remesas para aquellos que permanecen en Francia. La familia se construye con dificultades con el océano de por medio. Se expresa también un cierto mundo libertino 
que se refleja en la falta de futuro de los matrimonios, así, el honor se centra en tener un buen marido o recuperar a los pobres hijos de un descendiente que ha perdido la vida.

En estas misivas nos apropiamos de dos tiempos vividos de manera diferente, ${ }^{14}$ el de aquel que se queda y el del que se va. La espera de noticias para quien permanece en la tierra propia es una angustia constante, la lentitud retoma sus vidas a través del ansia de noticias. El que se va no sólo atraviesa aguas desconocidas, descubre otros lugares y una nueva concepción del tiempo, también afronta la vorágine del viaje y el difícil camino de emprender una vida distinta, algunas veces acompañado de parientes que ya tienen tiempo de habitar en la nueva tierra; enfrentan una realidad con otras características donde se revela una concepción diferente del tiempo; la luz y la obscuridad aparecen a otra hora, y varían las formas de alimentarse, de relacionarse y la necesidad de adquirir otra lengua para insertarse en la sociedad escogida. Las cartas sin retorno se constituyen en un tiempo muerto e inmóvil donde la ausencia se acrecienta y las preguntas permanecen sin respuesta. Las razones son múltiples: ingratitud, muerte, nueva vida, etcétera.

31 No nos extraña que muchas de las cartas tengan una escritura fonética, en algunos casos difícil de transcribir. Entonces, quiénes son esos hombres y mujeres que se van, a quién dejan en Francia, cuáles sentimientos se reflejan en la partida y cómo se nutren del imaginario sobre el país de llegada, son algunos de los elementos que escudriñamos a través de cartas, notas y hasta inventarios. Oficios y dedicación de los varones, acompañamientos y consejos de las hembras. Podríamos pensar que estos registros fonéticos son una característica de la escritura femenina. Quizá no lleguemos a conclusiones absolutas, pero sí podríamos decir que en un sector de trabajadores ello parece ser común.

\section{Para terminar}

Desde las sensibilidades, a través de diferentes temas y documentos hemos ensayado apropiarnos de historias de hombres y mujeres. Nuestra mirada ha atravesado un camino escarpado, un ir y venir donde viejos y nuevos conceptos como "sensibilidades", "afección" y "emociones" forman una unidad; otros conceptos, objeto de crítica, también han sido importantes. No hemos podido hacer caso omiso al término "mentalidades" pensando en el tiempo largo y su lentitud. Pero esta perspectiva no nos aleja de otro mundo, el de la memoria y la presencia del espectro, fundamentales para comprender el tiempo, la ausencia y el trauma, el cual se insinúa y es posible valorarlo en su doble desaparición, primero porque no es evidente, segundo porque ante la ley es siempre callado, sobre todo cuando llega la muerte. Y si pensamos el trauma y su doble ausencia, entramos también en ese mundo espectral, e inimaginable, no sólo porque siempre oculta su presencia, sino también porque otros, la ley, la crónica y la memoria oficial a fuerza de olvidarlo, lo cancelan.

Transitamos por otros parajes, el presente nos cala y no podemos dejar de lado a los migrantes que atraviesan fronteras en busca de seguridad o sustento. Ellos viajan con sus sueños apretujados en una pequeña mochila, por necesidad dejan atrás ese otro mundo tan propio y afrontan el camino con un sinnúmero de dificultades. En ese transitar, también corren el riesgo de perder la vida. En la muerte que se cierne sobre hombres y mujeres en México, el camino es el lugar del crimen y éste se examina con frialdad; los 
números son los que establecen la gravedad de la situación. En las muertes de ayer y hoy, el dolor sufrido por la víctima no es valorado.

En el levantamiento del cuerpo los expertos realizan las primeras consideraciones, así conocemos la condición social de la víctima, su manera de vestir e higiene. A partir de estos datos se conforma la opinión, imprescindible para la resolución del caso. En la introducción al libro de Ambroise Tardieu, Les attentats aux moeurs de 1857, Vigarello señala la subjetividad de los médicos legistas, quienes no pueden hacer caso omiso de sus obsesiones para valorar el cuerpo de las víctimas. Observación y moral se mezclan y fabrican estigmas físicos, “[...] traicionándose con sus juicios de valor”. (VIGARELLO, 1995: p.5-27). Y es ante la plancha que existe la posibilidad de preguntarnos: ¿cómo pensar el cuerpo de la víctima, la mano que a través del escalpelo y del speculum explora el daño causado, la contusión?, ¿cómo comprender al otro y a la otra, en el trauma que no puede expresarse por la ausencia de voz? A través del alegato, las palabras del juez y del médico legista se resuelve el caso. El dictamen es fijo, no explora más allá de la materialidad del cuerpo, los pormenores se reducen a la herida y a las lesiones que han provocado el deceso. En casos menores, una frase escueta salva la situación: la herida curará en menos de 15 días; a partir de esta aseveración no existe consecuencia para el victimario.

Aprehender lo vivido por la víctima, ¿es posible, si pensamos que las afecciones se encuentran enmarañadas entre lo público y lo privado, permeadas en varios ámbitos por la biopolítica y manifiestas desde la perspectiva del "impulso afectivo", en cualquiera de sus manifestaciones "pasionales, emocionales y sentimentales"?. En el caso del asesinato de mujeres, el trauma significa una doble ausencia, la de la voz y la de la vida. El horror y el dolor aparecen en las huellas dejadas en el cuerpo inerte y, en algunos casos, en la pena expresada por los familiares. Como lo señalaría Mabel Moraña, refiriéndose a Rancière, "el sistema social, en su forma policial de ordenamiento y disciplinamiento de las percepciones, afectos y formas de conocimiento de la realidad, produce una división entre lo que es visible o invisible, audible o inaudible, decible o indecible". (MORAÑA, SANCHEZ PRADO: p.313-337).

El trauma no parecería perceptible, valorado recientemente por los historiadores merece atención, pues como señala Cathy Caruth, esta "experiencia sobrecogedora" se produce debido "a un inesperado acontecimiento catastrófico en el cual la respuesta al evento ocurre con frecuencia de manera atrasada, incontrolado, repetitivo con la aparición de alucinaciones y otros fenómenos intrusivos". (CARUTH, 1996: p.10). Entonces, lidiamos con la ausencia, se trata de lo vivido no asimilado en el momento y que en los casos de asesinato no parece tener futuro. ¿Lo tendría en la palabra de los otros?, ¿en los traumas colectivos? De todas maneras, en palabras de Didi Huberman, (1912: p.18). "lo propio del archivo es su laguna, su naturaleza horadada".

\section{BIBLIOGRAFÍA}

CARUTH, Cathy. Unclaimed experience, Trauma, Narrative, and History, Baltimore. The Johns Hopkins University Press, 1996. 
CRAMAUSSEL, Chantal. "Imagen de México en los relatos de viaje franceses: 1821-1862", en el libro México Francia, Memoria de una sensiblidad común, siglos XIX-XX, Javier Pérez Siller (coordinador). BUAP, Colegios de San Luis, CEMCA, Puebla, 1998.

DAMASIO, Antonio. The strange order of things. Life, Feelind, ad the Making of Cultures. Pantheon Books, USA, 2018.

DAUHPIN, P. Lebrun-Pézerat, POUBLAN, D., Ces bonnes letters, Une correspondence familiale au XIX siècle, préface de Roger Chartier. Bibliothèque Albin Michel, Histoire, Paris, 1995.

DIDI-HUBERMAN, Georges. Arde la imagen. Serieve, Ediciones Ve, S.A. de C. V., México, 1912.

El Observador Médico, Órgano de la Sociedad Médica, Pedro Escobedo, agosto de 1908.

ESTRADA, Rosalina. “La prostitución en México, ¿Una mirada francesa?”, en el libro Curar, sanar y educar, Enfermedad y sociedad en México, siglos XIX y XX, Claudia Agostoni coordinadora. UNAM, BUAP, México, 2008.

Gaceta Médica de México, t. IV, n. 5, 31 de mayo de 1909.

GORBACH, Frida. “¿Circulación de conocimientos? Una crítica el difusionismo y una vuelta a la historia local. Dos estudios." (inédito).

HARTOG, Francois. Régimes D’Historicité, Présentisme et experience du temps. La librairie du XXI Siecle, Seuil, Paris, 2003.

HOYSTAD, Ole M., A History of the Heart. Reaktion Books, Londres, 2007.

LAVALLE CARVAJAL, Eduardo. "Profilaxis venérea, medios prácticos de fácil aplicación y de prontos resultados”, en Gaceta Médica de México, t. IV (3a serie), n. 5, 31 de mayo de 1909.

MARISTAIN, Mónica. "Nadie que quiera escribir hoy, puede olvidar a nuestros muertos" dice Cristina Rivera Garza. Sin Embargo, México, Julio 7, 2013.

THIÉRY DE MÉNONVILLE, Nicolas-Joseph. Traité de la culture du nopal et de l'éducation de la cochenille dans les colonies françaises de l'Amérique, précédé d'un voyage à Guaxaca. Préface, des Notes \& des Observations relatives à la culture de la Cochenille (édité par Veuve Herbault, Cap-Français, 1786, réédité en 1787). L'ouvrage est complété, selon le catalogue de la par son éloge Le Nopal (Paris, 1787).

MORAÑA, M., SÁNCHEZ PRADO, I., (editores) "Postscriptum”, en El lenguaje de las emociones. Afecto y cultura en América Latina. University of St. Louis, Vervuert, Madrid, 2012.

MORNET, Daniel. El pensamiento francés en el siglo XVIII, Ediciones Encuentro, España, 1988.

PALTI, Elías José. “The Problem Misplaces Ideas” Revisited: Beyond The "History of Ideas” en Latin America, Journal of the History of Ideas, Vol. 67, No. 1, enero 2006.

RIBAS-CASASAYAS, Alberto y PETERSEN, Amanda L., Espectros. Ghostly Hauntings in Contemporary Transhispanic Narratives, Lewisburg, Bucknell University Press, USA, 2016.

RICORD, Philippe. Traité de maladies vénériennes: ouvrage théorique et pratique, Chez Blosse. Libraire Éditeur, Paris, 1853.

RIVERA GARZA, Cristina. La muertes indóciles. Tusquets, México, 1913. Citado en el libro RIBASCASASAYAS, Alberto y PETERSEN, Amanda L., Espectros. Ghostly Hauntings in Contemporary Transhispanic Narratives. Lewisburg, Bucknell University Press editado por Alberto RibasCasasayas y Amanda L. Petersen, USA, 2016.

SAID, Edwar. Sobre el estilo Tardío. Debate, Pinguin Ramdom House Grupo Editorial, Barcelona, 2009. 
SOUST, Jeanne. “Cartas y palabras: los rostros de Eugène”, en Eugène Latapi, (1824-1868).

Coedición privada, Familia Latapí, Instituto de Ciencias Sociales y Humanidades, Puebla, 2004.

VIGARELLO, G., "La violence sexuelle et l'oeil du savant", TARDIEU, A., Grenoble, Les Attentats aux moeur, (1857), Jerome Millan, 1995.

WICKBERG, Daniel. What Is the History of Sensibilities? On Cultural Histories, Old and New, The American Historical Review, Volume 112, Issue 3. 2007.

\section{NOTAS FINALES}

1. RICORD, Philippe. Traité de maladies vénériennes: ouvrage théorique et pratique. Chez Blosse, Libraire Éditeur, Paris, 1853.

2. Gaceta Médica de México, t. IV, n. 5, 31 de mayo de 1909.

3. El Observador Médico, Órgano de la Sociedad Médica, Pedro Escobedo, agosto de 1908.

4. Ídem.

5. Ídem.

6. En un texto inédito GORBACH, Frida, reflexiona sobre la “¿Circulación de conocimientos? Una crítica el difusionismo y una vuelta a la historia local. Dos estudios".

7. FINLAY, Victoria. Color. A Natural History of the Palette, Random House Trade Paperbacks, New York, 2002, p. 150-151

8. Véase DAUHPIN, C., LEBRUN-PÉZERAT, P., POUBLAN, D. Ces bonnes letters, Une correspondence familiale au XIX siècle, préface de Roger Chartier. Bibliothèque Albin Michel, Histoire, Paris, 1995, pp. 99-190.

9. Para entender la importancia del ceremonial, véase el texto de SOUST, Jeanne. "Cartas y palabras: los rostros de Eugène", en Eugène Latapi (1824-1868), Coedición privada, Familia Latapí, Instituto de Ciencias Sociales y Humanidades, Puebla, 2004, pp.143-164.

10. Sólo pienso que, ahora sublevada, indignada, por lo que sucede en Nicaragua, aletargada en mí por muchos años, la sublevación de ellos, los jóvenes estudiantes, espacio que también habité en un tiempo, me permite sentir la sublevación por pequeñas y por grandes cosas.

11. En su introducción al libro póstumo de SAID, Edwar. Sobre el estilo Tardío. Debate, Pinguin Ramdom House, Grupo Editorial, Barcelona, 2009, p. 13.

12. MARISTAIN, Mónica. "nadie que quiera escribir hoy, puede olvidar a nuestros muertos" dice RIVERA GARZA, Cristina. Sin Embargo, Julio 7, 2013, a propósito de su texto Las muertes indóciles, Tusquets, citado en el libro Espectros. Ghostly Hauntings in Contemporary Transhispanic Narratives, Lewisburg, Bucknell University Press editado por RIBAS-CASASAYAS Alberto y PETERSEN, Amanda L., 2016, pp. 1-11.

13. CADN, Caja No. 26, Fondo Vera Cruz. Carta de Fernand Locatelli a su suegra, Madame Thile s/f. 14. Pensar en Hartog y en los regímenes de historicidad que él plantea nos lleva a considerar también esta variante, el tiempo vivido es en realidad el otro tiempo. HARTOG, Francois. Régimes D’Historicité, Présentisme et experience du temps. La librairie du XXI Siecle, Seuil, Paris, 2003.

\section{RESÚMENES}

Cruzar la frontera desde el mar adquiere otro significado, los puertos de partida y de llegada son, desde el afecto y la cultura, un paisaje a rememorar. Aquellos hombres y mujeres que llegan desde Francia a México, quizá a Veracruz, cargan con su pasado. En el cruce del océano 
construyen las palabras de la nostalgia, las cuales cobran vida en la correspondencia. Thiery de Menonville viaja a Oaxaca en el siglo XVIII con un claro propósito: apropiarse de la cochinilla para cultivarla en Santo Domingo; en la travesía observa la naturaleza y a los habitantes, admira el entorno, pero su corazón bate con prisa al observar a una bella mujer y al aproximarse a la posesión de su tesoro rojo grana. Desde la perspectiva de las sensibilidades, como diría Wickberg, transitamos de las representaciones hacia las formas de percepción y sentimiento. Situamos a Menonville en su tiempo como un ilustrado del siglo XVIII; de acuerdo con Mornet, estos hombres habrían conocido todas las formas del pensamiento contemporáneo. Libros e ideas también viajan y se instalan de peculiar manera, Parent du Châtelet es un ejemplo, sus planteamientos se encuentran inmersos en la disputa entre reglamentaristas y abolicionistas. Desde la ausencia, las subjetividades nos introducen en ese mundo habitado por múltiples espectros.

Franchir la frontière depuis la mer prend une autre signification; les ports de départ et d'arrivée sont, pour l'attachement et la culture, un paysage à évoquer. Ces hommes et ces femmes qui arrivent de la France au Mexique, peut-être à la ville de Veracruz, portent le poids de leur passé. En traversant l'océan, ils composent les mots de la nostalgie, et ces mots s'animent dans leur correspondance.

Thierry de Ménonville part à Oaxaca au XVIIIe siècle avec un but précis : s'approprier de la cochenille pour son élevage à Saint-Domingue ; pendant la traversée, il observe la nature et les habitants, il admire l'environnement, mais les battements de son cœur s'accélèrent à la vue d'une belle femme et à l'approche de son trésor rouge cramoisi. Si l'on se place dans la perspective des sensibilités, comme dit Wickberg, nous passons des représentations à des formes de perception et de sentiment. Nous situons Ménonville dans son temps comme un homme des Lumières du XVIIIe siècle ayant connu, selon Mornet, toutes les formes de la pensée contemporaine. Les livres et les idées voyagent aussi et trouvent leur place d'une façon qui leur est singulière. Parent du Châtelet en est un exemple. Ses raisonnements d'hygiéniste sur la prostitution se trouvent ainsi immergés dans la dispute entre les réglementaristes et les abolitionnistes : quand elle voyage, toute pensée rencontre des mondes habités par des nombreux spectres.

\section{ÍNDICE}

Mots-clés: Migration, Mexique-France, idées, mots, sensibilités

Palabras claves: migración, México-Francia, Ideas, palabras, sensibilidades.

\section{AUTOR}

\section{ROSALINA ESTRADA URROZ}

Instituto de Ciencias Sociales y Humanidades

Benemérita Universidad Autónoma de Puebla

restrada47@yahoo.com 